\title{
Remote monitoring and real-time abatement of odor emitted from sewer using odor sensors, wireless communication technique and microbial deodorant
}

Park S.J.*

School of Rail-road Construction \& Environmental Eng., Woo Song University, Daejeon 34606, Republic of Korea

Received: 30/04/2018, Accepted: 30/10/2018, Available online: 02/11/2018

*to whom all correspondence should be addressed: e-mail: sjpark@wsu.ac.kr

https://doi.org/10.30955/gnj.002740

\section{Abstract}

In this study, a new technology was introduced to monitor the odor occurrence situation at the remote site in real time and the technology to reduce sewage odor by using microbial deodorant. Long-term monitoring and full-scale test was carried out to investigate the odor concentration in the combined sewer using the real - time odor monitoring device which consist of 3 odor sensors with the wireless communication technique, and to investigate the effect of the microbial deodorant on the reduction of sewer odor. The odor monitoring device, which was fabricated using metal oxide semiconductor sensors and code division multi access communication technique, was installed at three sites of the gravity-flow type combined sewer (depth $3 \mathrm{~m}$ and width $5 \mathrm{~m}$ ) in Gangnam, Seoul. Odor monitoring in field was carried out at the interval of 10 minutes for 304 days over the autumn, winter and summer. The measured results were transmitted to Woosong odor research center about $100 \mathrm{~km}$ away from the site. The measured sensor value was converted to olfactory odor concentration by the co-relation equation of the sensor value and the olfactory odor concentration. As the monitoring results, more than 40,000 sewage odor data were obtained. The average odor concentration of raw sewage in combined sewer was 464 $\mathrm{OU}_{\mathrm{k}}$, which was $321 \mathrm{OU}_{\mathrm{k}}$ in winter and $412 \mathrm{OU}_{\mathrm{k}}$ in autumn and $659 \mathrm{OU}_{\mathrm{k}}$ in summer. The commercial microbial deodorant used in this study was the mixture culture of 48 microbial strains, and the microbial deodorant of $1 \mathrm{~m}^{3} \mathrm{~d}^{-1}$ to $2 \mathrm{~m}^{3} \mathrm{~d}^{-1}$ was mixed with raw sewage at the $1.5 \mathrm{~km}$ upstream of the site where odor complaints occurred. As the experimental results, the average odor concentration of sewage mixed with microbial deodorant was $113 \mathrm{OU}_{\mathrm{k}}$, which was $102 \mathrm{OU}_{\mathrm{k}}$ in winter and $298 \mathrm{OU}_{\mathrm{k}}$ in autumn and $153 \mathrm{OU}_{\mathrm{k}}$ in summer. It was estimated that the odor reduction effect of sewer odor by microbial deodorant is about $74 \%$.

Keywords: Sewer odor, odor sensor, microbial deodorant, odor abatement, olfactory odor estimation.

\section{Introduction}

Malodorous gases emitted from sewer system is attracting attention as a major social issue that takes from the quality of living environments. Sewer and its facilities such as manholes and basins which discharge odor in an urban area are making it difficult to reduce odor. Most of old large cities have combined sewer systems, and organics in sewage are likely to deposit in the bottom of sewer during a dry season because of low sewage velocity in a sewer, so it is easy to generate malodorous gas such as $\mathrm{H}_{2} \mathrm{~S}$ in anaerobic conditions. In addition, septic tanks and building drainage tanks connected to sewer pipes are causing the sewer odor to increase (Japan Association of Odor Environment, 1992).

The Odor Prevention Law was enacted in 2005, a lot of R\&D projects related to odor have been carried out. As a result, odor problems of factories in industrial complexes have been almost solved, but in recent years, odor emitted from living environments such as direct fire roast restaurants and sanitary sewer have become major causes of civil complaints. When the G20 Summit was held in Seoul in 2010, sewer odor problems of the downtown area were raised to be a very urgent issue to resolve (Seoul Development Institute, 2009; Seoul Seocho District, 2010; Seoul Metropolitan City, 2018).

Many studies to reduce sewage odor have been studied for long time. The abatement technology of sewer odor can be classified into liquid-phase control technique and vaporphase control technique. Liquid phase techniques have been reported by the injection of air, oxygen, oxidant chemicals such as $\mathrm{H}_{2} \mathrm{O}_{2}, \mathrm{NaOCl}$ and $\mathrm{KMnO}_{4}$, and by the adjustment of $\mathrm{pH}$ such as $\mathrm{NaOH}$, including the injection of iron salts such as $\mathrm{FeCl}_{3}$ and $\mathrm{Fe}_{4} \mathrm{O}_{4}, \mathrm{Ca}\left(\mathrm{NO}_{3}\right)_{2}$. Chen et al. (2000) reported a case of reducing sewage odor by injecting oxygen into a $1.5 \mathrm{~km}$ gravity sewer. Dan et al. (2008) reported a case study of iron salts injection methods to effectively remove $\mathrm{H}_{2} \mathrm{~S}$ in sewers. Mathioudakis et al. (2006) reported that $\mathrm{H}_{2} \mathrm{~S}$ was reduced economically and effectively by continuously injecting $10 \mathrm{~kg} \mathrm{NH}_{4} \mathrm{NO}_{3} \mathrm{hr}^{-1}$ into a $\quad 6.7 \mathrm{~km}$ combined sewer pipe. 
Penter et al. (1999) reported that $\mathrm{H}_{2} \mathrm{~S}$ was effectively reduced by $\mathrm{Ca}\left(\mathrm{NO}_{3}\right)_{2}$ injection into a 2,500 feet pressure sewer. Schattovits et al. (2000) reported a case study comparing the odor reduction effect by injecting calcium nitrate and ferric sulfate/nitrate into an $18 \mathrm{~km}$ pressure sewer. Lehua et al. (2008) reported a $\mathrm{H}_{2} \mathrm{~S}$ control using a microbial fuel cell (MFC) in a more economical way than previously used. The vapor phase technique includes ventilation, collection of sewage odor and removal using a treatment device such as a scrubber, an adsorption tower or biofilter. Robert et al. (2002) reported a case in which sewage odor complaints were reduced by using vapor phase control such as dry scrubber with liquid phase control techniques which inject iron salts and nitrate compounds to solve the sewer odor problem, simultaneously. However, most of the studies that have been carried out so far are few cases of biological treatment with microbial deodorant as chemical treatment using chemicals.

In order to manage the sewage odor, even if various abatement techniques are applied in the field, a means for effectively evaluating the abatement effect is needed. Generally, odor is evaluated using human olfactory. In Europe, USA and Australia, dynamic olfactometer is used. In Japan, Korea and China, air dilution bag method is used. However, since these methods are carried out by collecting the samples from the field and analyzing them by the laboratory, there are limitations in understanding the odor occurrence situation due to time variation and effectively responding to the odor complaints. Recently, a real-time and on-line odor monitoring technique in the field using odor sensor has been widely used. Various sensors have been used for an odor analysis, including a portable $\mathrm{H}_{2} \mathrm{~S}$ sensor and $\mathrm{H}_{2} \mathrm{~S}$ continuous measurement device in the field. In addition, as IT techniques have developed, an odor sensor device with wireless communication technique has been used. Cipriani et al. (2017) reported the case of measuring the $\mathrm{H}_{2} \mathrm{~S}$ concentration by $\mathrm{H}_{2} \mathrm{~S}$ electronic sensor for one month while investigating the removal by chemical oxidants. Park et al. (2009) reported that the $\mathrm{H}_{2} \mathrm{~S}$ continuous measuring instrument with data logger inside the manhole was installed inside the sewer manhole and continuously monitored $\mathrm{H}_{2} \mathrm{~S}$ concentration and the effect of the $\mathrm{H}_{2} \mathrm{~S}$ reduction by microbial deodorant. Pan et al. (2009) report on the real-time monitoring of livestock odor using electric network system. Son et al. (2015) report real-time monitoring of odor compounds in water using bioelectronic sensors. Ishida et al. (2000) reported a case study of real-time imaging of odor flow in a space using a gas sensor array. It is known that $\mathrm{H}_{2} \mathrm{~S}$ is a representative odor substance generated in sewer, but Kim et al. (2006) reported that not only $\mathrm{H}_{2} \mathrm{~S}$ but also other odorous substances are mixed in sewage, and Witherspoon et al. (2017) report that when establishing San Mateo city sewerage measures, it also established a reduction scheme for non-hydrogen sulfide in addition to hydrogen sulfide.
Although gas sensors for odor measurement are widely used for MOS sensors and EC sensors, and PID sensors for VOC measurement, it is known that MOS sensor is more effective for mixed odor measurement than EC sensors that react only with specific compounds. Lei et al. (2014) reports positive characteristics of cross-sensitivity, broad spectrum response and low-cost characteristics for MOS gas sensor, and Joo et al. (2006) reported that a MOS gas sensor is effective for evaluating sewage odors in which many malodorous compounds are mixed in addition to $\mathrm{H}_{2} \mathrm{~S}$.

However, the measurement of MOS odor sensor has an advantage to detect the tendency of odor generated in the sewer in a short time, but there is a limitation in evaluating the odor concentration of sanitary sewer by sensor measurement value or $\mathrm{H}_{2} \mathrm{~S}$ concentration. In order to respond to odor complaints felt by humans, it is necessary to provide a means of expressing the measured sensor value as sensory odor concentration. Shakoorjavan et al. (2016) reported the correlation between sensor measurements and olfactory evaluation values and reported the results of a study to diagnose odor concentration using sensor measurement results.

Under the background above, this study was carried out to evaluate continuously odors emitted from a combined sewer in real-time, using an on-site odor sensor and a wireless communication technique rather than off-line odor evaluation by grab sampling and analysis. Another purpose of this study was to investigate the degree of sewage odor reduction by injecting microbial deodorant into the sewage rather than injecting the chemicals that have been used so far.

\section{Material and methods}

\subsection{Sewer conditions of the study area}

This study was conducted in the downtown of Seoul Gang Nam district, and the target sewer in this study is a box culvert and a gravity-flow combined sewer. The inside and outside of the box culverts were surveyed to understand the condition of the target sewer. According to the survey results, the amount of flowing sewage in the sewer during the dry season was about $10 \% \sim 30 \%$ of the cross section of the sewer, and the average flow rate was about $9 \mathrm{~m}^{3} \mathrm{~min}^{-1}$ and the average flow velocity $0.137 \mathrm{~m} \mathrm{~min}^{-1}$. Benthal deposits in the sewer varied from $10 \%$ to $83 \%$ of the depth of the water, and the mean depth of sediments was $0.223 \mathrm{~m}$. Figure 1 shows the location of the study area, and the target sewer condition of odor monitoring points is shown in Table 1.

\subsection{Real time odor monitoring by odor sensor device with wireless communication technique}

Odor sensor device to monitor inner odor concentration of sewer was fabricated with the collaboration of metal oxide semi-conductor sensor (Figaro TG 2602, Italy) Odor sensor data measured at 10 minute intervals on the site were designed to be transmitted to the Woo Song University Odor Research Center located in Daejeon city, 100 km away from the study area, using code division multiple access 
technique which enables two-way communication in a real time.

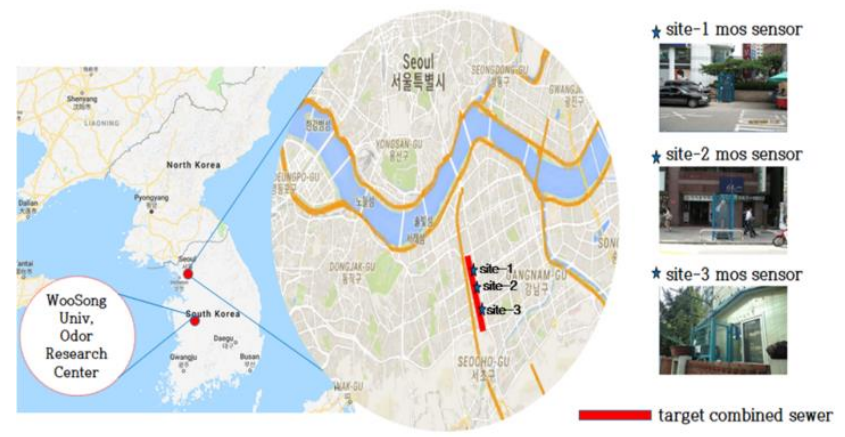

Figure 1. Location of the study area

Table 1. Surveyed results of the target combined sewer in this study

\begin{tabular}{cccccc}
\hline Site & $\begin{array}{c}\text { Diameter } \\
\text { (width } \times \\
\text { height, } \\
\mathbf{m})\end{array}$ & $\begin{array}{c}\text { Water } \\
\text { depth } \\
(\mathbf{m})\end{array}$ & $\begin{array}{c}\text { Benthal } \\
\text { deposits } \\
(\mathbf{m})\end{array}$ & $\begin{array}{c}\text { Flow } \\
\text { rate } \\
\left(\mathbf{m}^{3}\right. \\
\left.\text { sec }^{-1}\right)\end{array}$ & $\begin{array}{c}\text { Mean } \\
\text { velocity } \\
(\mathbf{m ~ s e c} \\
\mathbf{1})\end{array}$ \\
\hline 1 & $5.0 \times 2.5$ & 0.28 & 0.14 & 0.217 & 0.310 \\
\hline 2 & $2.0 \times 3.0$ & 0.6 & 0.50 & 0.009 & 0.047 \\
\hline 3 & $5.0 \times 3.5$ & 0.94 & 0.10 & 0.224 & 0.053 \\
\hline Average & & 0.517 & 0.233 & 0.15 & 0.137 \\
\hline
\end{tabular}

\subsection{Olfactory odor estimation by air dilution sensory method of Korea}

In Korea, air dilution sensory method has been used as an olfactory odor estimation technique. The air dilution sensory method is divided into three stages: the first stage is to select five panelists, the second is that odor detection is performed according to the dilution rate of raw odor sample by each panelists, and the third is that odor concentration is calculated using the estimated results of five panelists. The person to match the type of smell and the odor intensity required in the test criteria for the four reagents is selected as the panelist. Acetic acid, Trimethylamine, Methylcyclopentenolone and B-Penylethylalcohol are used as representative reagents for the panelist selection. The odor intensity is divided into five levels using $0.1 \mathrm{ml} / \mathrm{L}$ of $300 \mathrm{ml} / \mathrm{L}$ $\mathrm{n}$-Butanol solution and headspace method. The evaluation of the odor concentration of the site sample was performed by providing two bags collected with odor free air and one bag injected with diluted site samples, and then five panelists record the number of the bag injected with the odor sample. The dilution test of the field sample is carried out until the panelist who has the correct answer becomes one person. In the calculation of the odor concentration of the odor sample, the data of the first and the last panelist of the wrong answer delete in the evaluation results of five panelists, and calculates the geometric mean of the evaluation results of the remaining three panelists. The dilution rate of the geometric mean calculated is used as odor concentration, and is expressed in units of $\mathrm{OU}_{\mathrm{k}}$. Table 2 shows the estimation process of odor sample by air dilution sensory method in Korea, and the process of calculating odor concentration $\mathrm{OU}_{\mathrm{k}}$ of samples by using analytical results is shown in Table 3.

Table 2. Evaluation process of odor sample in Korea (example)

\begin{tabular}{|c|c|c|c|c|c|}
\hline \multirow[b]{2}{*}{ Panelist } & \multicolumn{2}{|c|}{$1^{\text {st }}$ Test } & \multirow{2}{*}{$\begin{array}{c}2^{\text {nd }} \\
\text { Test } \\
(x 30)\end{array}$} & \multirow{2}{*}{$\begin{array}{c}3^{\text {rd }} \\
\text { Test } \\
(\times 100)\end{array}$} & \multirow[b]{2}{*}{ Remark } \\
\hline & (x10) & (x10) & & & \\
\hline A & $x$ & $\mathrm{O}$ & & & \multirow{2}{*}{$\begin{array}{l}\text { Dilution } \\
\text { rate in } \\
\text { parenthesis }\end{array}$} \\
\hline B & 0 & 0 & $\mathrm{O}$ & $\begin{array}{c}0 \\
\text { (next } \\
\text { test }\end{array}$ & \\
\hline & & & & stop) & \multirow{3}{*}{$\begin{array}{l}\mathrm{O} \text { is correct } \\
\text { answer }\end{array}$} \\
\hline$C$ & 0 & $x$ & & & \\
\hline $\mathrm{D}$ & 0 & 0 & 0 & & \\
\hline$E$ & 0 & 0 & $x$ & & $\begin{array}{c}\mathrm{X} \text { is wrong } \\
\text { answer }\end{array}$ \\
\hline
\end{tabular}

Table 3. Calculation process of odor concentration, $\mathrm{OU}_{\mathrm{k}}$ in Korea (example)

\begin{tabular}{|c|c|c|c|}
\hline Panelist & $\begin{array}{c}\text { Calculation } \\
\text { of } \mathrm{OU}_{\mathrm{k}}\end{array}$ & Remark & $\begin{array}{c}\mathrm{OU}_{\mathrm{k}} \text { of the } \\
\text { sample }\end{array}$ \\
\hline A & $\begin{array}{l}(3 \times 10)^{\wedge} \\
0.5=5.477\end{array}$ & $\begin{array}{l}\text { Not use } \\
\text { the } \\
\text { minimum }\end{array}$ & \\
\hline B & 100 & $\begin{array}{l}\text { Not use } \\
\text { the } \\
\text { maximum }\end{array}$ & $\begin{array}{c}(5.477 \times 30 \times \\
10)^{\wedge}(1 / 3)=11.8\end{array}$ \\
\hline C & $\begin{array}{l}(3 \times 10)^{\wedge} \\
0.5=5.477\end{array}$ & Use & \\
\hline D & 30 & Use & \\
\hline$E$ & 10 & Use & \\
\hline
\end{tabular}

2.4. Evaluation of the sensory odor concentration in a sewer using the monitoring results by odor sensors at field

The odor sensor used in this study is a device to measure potential difference caused by contact oxidation of metal oxide semiconductor surface with odor substances contained in gas. For this reason, odor sensor value provided in $\mathrm{mV}$ cannot offer directly sensory odor concentration expressed as $\mathrm{OU}_{\mathrm{k}}$ or olfactory odor intensity that a human smells.

To obtain the conversion equation of the sensor value and the sensory odor concentration $\mathrm{OU}_{\mathrm{k}}$, nine samples prepared by the on-site odor sample and odor free air were evaluated at the same time. The sensor value data for 9 samples were obtained from 3 on-site odor sensor devices and the olfactory odor concentration was measured at laboratory using the air dilution sensory test method of Korea (National Institute of Environmental Research, 2005). Using the experimental results obtained at the same time, correlation equation between the sensor measurement value $\mathrm{mV}$ and the olfactory odor concentration $\mathrm{OU}_{\mathrm{k}}$ was made. Figure 2 shows the procedure of deriving the correlation equation between the sensor measurement value and the sensory odor concentration, and Figure 3 is the working photograph for deriving the correlation equation in the field. 


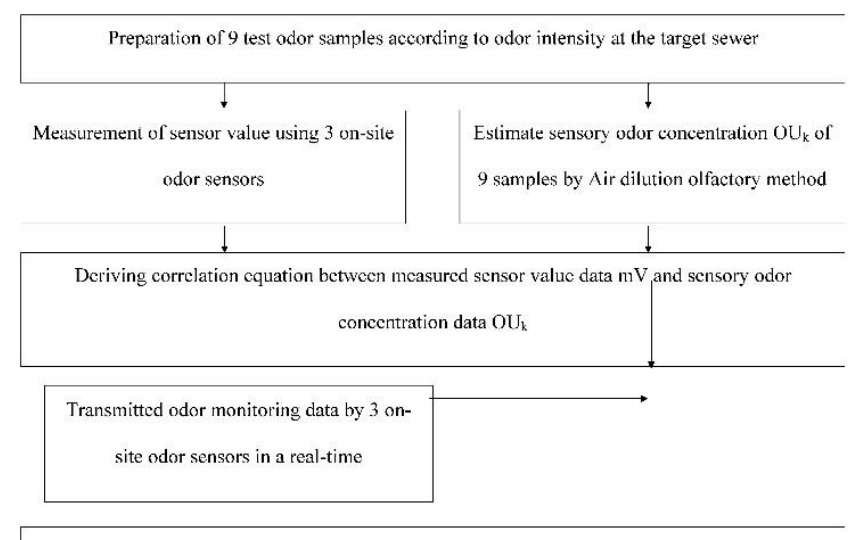

Acquisition of sensory odor concentration data converted by correlation equation

Figure 2. Procedure of deriving the correlation equation between the measured sensor value and the sensory odor concentration

\subsection{Microorganism deodorant used in this study to abate sewer odor intensity}

Microbial deodorants used in this study was determined from the previous study results. In the previous study, the lab-scale $\mathrm{H}_{2} \mathrm{~S}$ removal test was carried out for four microbial deodorants on the market. As the experimental results, the microbial deodorant KS50 (Geon-nong Co., Korea) showed the highest removal efficiency for a raw sewage odor that the concentration of $\mathrm{H}_{2} \mathrm{~S}$ was decreased to $50 \%$ at about 90 minutes after the KS50 injection (Park S.J., 2010). The selected microbial deodorant KS50 is a mixed culture of 48 Bacillus strains which is shown in Table 4. During the experimental period of this study, $1 \mathrm{~m}^{3}$ to $2 \mathrm{~m}^{3}$ of KS50 in a day was injected into the sewer at $1.8 \mathrm{~km}$ upstream, considering the flow rate of sewage and inner odor intensity in the sewer.

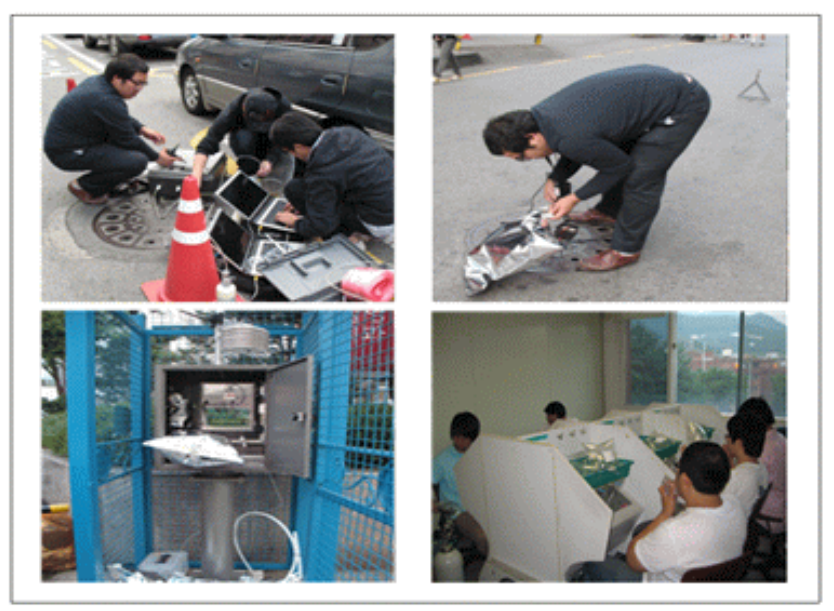

Figure 3. The working photograph to investigate the on-site odor sensor data and the sensory odor concentration data

2.6. Full-scale experimental condition to investigate the effect of microbial deodorant KS50

As shown in Table 5, total 5 tests were performed to investigate the inner odor concentration of combined sewer which raw sewage (or sewage mixed with microbial deodorant KS50) is flowing, according to the seasonal variation - summer, autumn, and winter. Test \#1, Test \#3 and Test \#4 were conducted to investigate the odor concentration emitted from, and Test \#2, Test \#5 to investigate the inner sewer odor concentration after reduction of odor concentration by the microbial deodorant KS50 in the combined sewer.

Field tests were conducted for 304 days during autumn, winter and summer. Odor concentration of raw sewage was investigated for 151 days, and sewage mixed with microbial deodorant KS50 for 153 days. In order to investigate the optimum dilution rate of microbial deodorant injected into sewage, dilution rate of raw KS50 solution was divided into 50 times (Test \# 2-A), 30 times (Test \# 2-B) and (Test \# 2-B) 20 times respectively. In the final experiment (Test \# 5), the optimal dilution rate was determined to be 30 times, and the Test \#5 experiment was performed in the summer which the highest odor concentration in the sewer occurs.

\section{Results and discussion}

3.1. Sewer odor monitoring results in real-time and remote by odor sensor device and wireless communication technique

Test \#1 experiment was conducted for 50 days to investigate odor concentration emitted from a raw sewage, and then Test \# 2 was performed while microbial deodorant KS50 by dilution conditions of raw KS50 solutionwas mixed with the flowing sewage for 90 days. Test \#3 was conducted for 45 days in order to investigate the odor concentration of raw sewage at the condition of low temperature in winter. In order to investigate the odor concentration of raw sewage in summer which relatively high odor is generated, the experiment of Test \#4 for 56 days was carried out. In order to investigate the odor reduction effect by the microbial deodorant KS50, The experiment of Test \#5 for 56 days was carried out continuously. Even though the study area was located 100 $\mathrm{km}$ from the odor control center, the real-time odor data monitored by on-site odor sensor was downloaded in the form of an excel file to the desktop PC by code division multiple access communication technique, as shown in Figure 4. During the 304 days of this experiment, the odor data of 131,328 in total from three sites was collected by three odor monitoring devices. Figure 5 illustrates the screen of desk-top PC showing the time-course variation of odor generation in the target sewer at 3 sites for 192 days during the period of Test \#1 (A) to Test \#3 (E)). In Figure 5 , (A) (Test \#1) and (E) (Test \#3) show the status of odor generation of raw sewage in sewer, while Test \#2 (B), (C), (D) shows the reduced odor concentration by the microbial deodorant KS50. As shown in Figure 5, comparing observed odor data of Test \#1 ( A ) and Test \#3 (E)) and Test \#2 (B),C),(D)), it was appeared that there was a significant difference of odor concentration in sewer, depending on the microbial deodorant KS50 injection. And the abatement of microbial deodorant KS50 to sewer odor was found to be different according to the dilution ratio of raw KS50 solution. As shown in 
Figure 5, it was appeared that the reduction effect of 20 times (Test \#2(C) and 30 times (Test \#2(D)) of dilution rate were higher than the one of 50 times (Test \#2 (B)). In addition, the results of the seasonal experiments show that the monitored odor data of Test \#1(A) in summer were higher than the one of Test \#3( (E)) in winter. Based on these monitoring data, it was obviously estimated that odor intensity of sewer odor in summer is stronger than the one in winter.

Table 4. Microbial strains in microbial deodorants KS50 used in this study

\begin{tabular}{|c|c|c|c|c|c|}
\hline No & Microbial strain & No & Microbial strain & No & Microbial strain \\
\hline 1 & Actinomyces sp. & 17 & Bacillus thermoamylovorans & 33 & Micrococcus sp. \\
\hline 2 & Bacillus anthracis & 18 & Bifidobacterium sp. & 34 & Norcadia sp.(IFM0137) \\
\hline 3 & Bacillus badius & 19 & Bordetella avium & 35 & Paenibacillus cineris \\
\hline 4 & Bacillus badius & 20 & Bordetella hinzii & 36 & Pediococcus pentosaceus(LM263) \\
\hline 5 & Bacillus cereus & 21 & Bordetella petrii & 37 & Ralstonia detusculanense \\
\hline 6 & $\begin{array}{c}\text { Bacillus } \\
\text { licheniformis }\end{array}$ & 22 & Clostridium butyricum & 38 & Actinomyces sp. \\
\hline 7 & $\begin{array}{c}\text { Bacillus } \\
\text { marismortui }\end{array}$ & 23 & Enterobacter hormaechei & 39 & Bacillus anthracis \\
\hline 8 & $\begin{array}{c}\text { Bacillus } \\
\text { megaterium }\end{array}$ & 24 & Enterobacter sp. & 40 & Bacillus badius \\
\hline 9 & Bacillus oleronius & 25 & Enterobacter sp.(B901-2) & 41 & Bacillus badius \\
\hline 10 & Bacillus sonorensis & 26 & Enterococcus faecalis & 42 & Bacillus cereus \\
\hline 11 & $\begin{array}{c}\text { Bacillus sp. KS- } \\
\text { 1(TUT1206) }\end{array}$ & 27 & Lactobacillus acidophilus & 43 & Bacillus licheniformis \\
\hline 12 & Bacillus sp. KS-2 & 28 & Lactobacillus sp. & 44 & Bacillus marismortui \\
\hline 13 & $\begin{array}{c}\text { Bacillus sp. KS-3(Q- } \\
12) \\
\end{array}$ & 29 & Leuconostoc paramesenteroides & 45 & Bacillus megaterium \\
\hline 14 & Bacillus sp.(NK13) & 30 & $\begin{array}{c}\text { low } \mathrm{G}+\mathrm{C} \text { Gram positive } \\
\text { bacterium(M51) }\end{array}$ & 46 & Bacillus oleronius \\
\hline 15 & Bacillus subtilis & 31 & Microbacterium estermaticum & 47 & Bacillus sonorensis \\
\hline 16 & Bacillus subtilis & 32 & Microbacterium sp.(YK18) & 48 & Bacillus sp. KS-1(TUT1206) \\
\hline
\end{tabular}

3.2. Odor concentration of malodorous gas emitted from raw sewage in a combined sewer

Table 6 shows the summarized results of the odor concentration data of raw sewage in the target sewer measured at 10-minute intervals at 3 sites for 151 days over the autumn, winter, and summer. As shown in Table 6, even though there are some differences depending on the time and on the site, the odor concentration of raw sewage in a gravity flow-type combined sewer varied from $261 \mathrm{OU}_{\mathrm{k}}$ to $894 \mathrm{OU}_{\mathrm{k}}$ on average $464 \mathrm{OU}_{\mathrm{k}}$. By the season, it was appeared that average odor concentration in summer is $659 \mathrm{OU}_{\mathrm{k}}, 321 \mathrm{OU}_{\mathrm{k}}$ in autumn and $321 \mathrm{OU}_{\mathrm{k}}$ in winter.

Table 5. Experimental conditions to investigate the odor concentration emitted from raw sewage and the sewage mixed with the microbial deodorant KS50

\begin{tabular}{|c|c|c|c|c|c|c|}
\hline Test & & Source & $\begin{array}{l}\text { Dilution rate to raw } \\
\text { KS50 solution }\end{array}$ & Period (days) & Season & $\begin{array}{l}\text { Mark in } \\
\text { Figure } 5 \\
\end{array}$ \\
\hline \multicolumn{2}{|c|}{$\# 1$} & Raw sewage & - & `09.09.01 '09.10.20 (50) & \multirow{2}{*}{ Autumn } & (A) \\
\hline \multirow{3}{*}{$\# 2$} & $\# 2-A$ & \multirow{3}{*}{$\begin{array}{l}\text { Sewage mixed with } \\
\text { KS50 }\end{array}$} & 50 times & '09.10.21 09.11 .05 (57) & & (B) \\
\hline & \#2-B & & 30 times & '09.11.06 09.12 .03 (27) & \multirow{3}{*}{ Winter } & (C) \\
\hline & $\# 2-\mathrm{C}$ & & 20 times & '09.12.04 '09.12.17 (13) & & (D) \\
\hline \multicolumn{2}{|c|}{ \#3 } & Raw sewage & - & `09.12.18 - `10.02.28 (45) & & (E) \\
\hline \multicolumn{2}{|c|}{$\# 4$} & Raw sewage & - & ‘10.06.01 - `10.07.26 (56) & \multirow[b]{2}{*}{ Summer } & - \\
\hline \multicolumn{2}{|c|}{$\# 5$} & $\begin{array}{l}\text { Sewage mixed with } \\
\text { KS50 }\end{array}$ & 30 times & ${ }^{\prime} 10.07 .26-` 10.09 .20(56)$ & & - \\
\hline
\end{tabular}




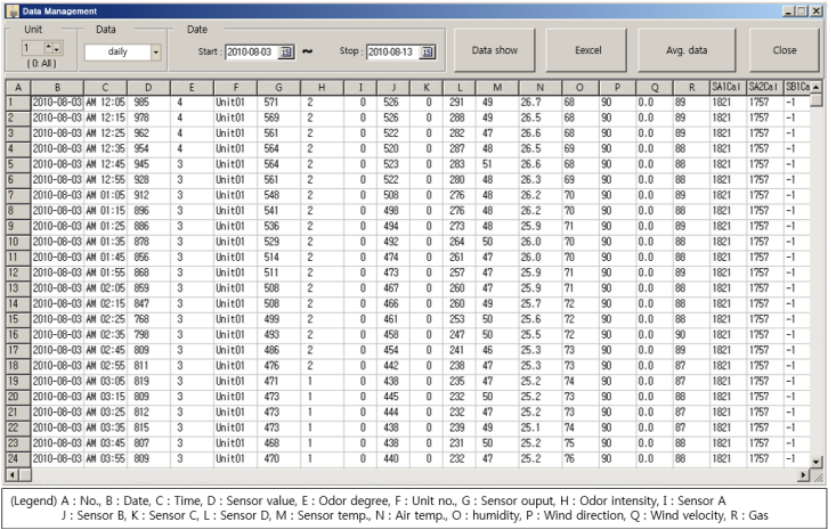

Figure 4. On-line monitoring odor data transmitted in the form of an excel file by on-site odor sensor devices

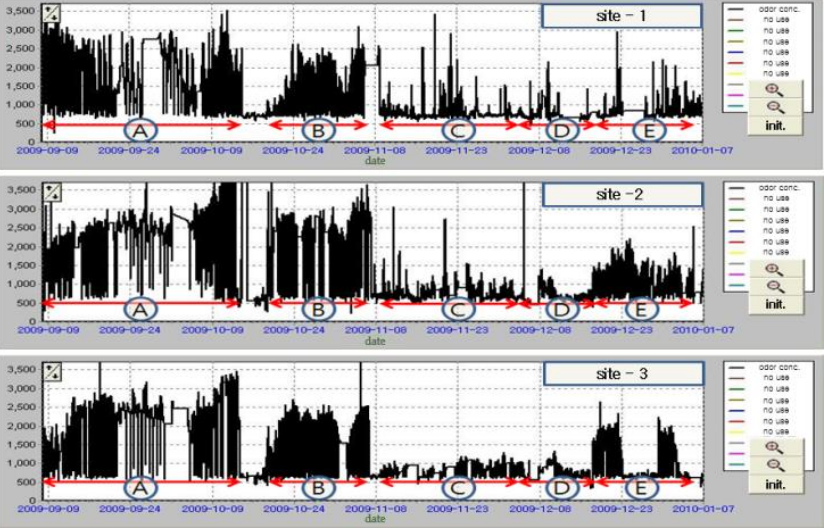

Figure 5. Time-course variation graph of sewer odor data monitored by on-site 3 odor sensors which display in the computer screen

Table 6. Odor concentration of malodorous gas emitted from raw sewage in a gravity-flow combined sewer

\begin{tabular}{|c|c|c|c|c|c|c|c|}
\hline \multirow{2}{*}{ Test } & \multirow{2}{*}{ Date } & \multirow{2}{*}{$\begin{array}{l}\text { Period } \\
\text { (days) }\end{array}$} & \multicolumn{4}{|c|}{ Odor concentration of gas emitted from raw sewage $\left(\mathrm{OU}_{\mathrm{k}}\right)$} & \multirow{2}{*}{ Season } \\
\hline & & & Site-1 & Site-2 & Site-3 & Avg. & \\
\hline$\# 1$ & $` 09.09 .01-` 09.10 .20$ & 50 & 498 & 415 & 323 & 412 & Autumn \\
\hline$\# 3$ & '09.12.18 - '10.02.28 & 45 & 261 & 391 & 311 & 321 & Winter \\
\hline$\# 4$ & $` 10.06 .01$ - '10.07.26 & 56 & 361 & 894 & 722 & 659 & Summer \\
\hline Avg. & & & 373 & 567 & 452 & 464 & \\
\hline
\end{tabular}

Table 7. Odor concentration of malodorous gas emitted from sewage mixed with microbial deodorant KS50 in a gravity-flow combined sewer

\begin{tabular}{|c|c|c|c|c|c|c|c|c|c|}
\hline & \multirow{2}{*}{ Test } & \multirow{2}{*}{$\begin{array}{l}\text { Dilution } \\
\text { rate to raw } \\
\text { KS50 } \\
\text { solution } \\
\text { (times) } \\
\end{array}$} & \multirow{2}{*}{ Date } & \multirow{2}{*}{$\begin{array}{l}\text { Period } \\
\text { (days) }\end{array}$} & \multicolumn{4}{|c|}{$\begin{array}{l}\text { Odor concentration of sewage mixed with } \\
\text { microbial deodorant KS50 }\left(\mathrm{OU}_{\mathrm{k}}\right)\end{array}$} & \multirow{2}{*}{ Season } \\
\hline & & & & & Site-1 & Site-2 & Site-3 & Avg. & \\
\hline \multirow{5}{*}{$\# 2$} & $\# 2-A$ & 50 & $\begin{array}{l}09.10 .21 \sim \\
` 09.11 .05\end{array}$ & 57 & 186 & 235 & 174 & 198 & Autumn \\
\hline & \#2-B & 30 & $\begin{array}{l}09.11 .06 \sim \\
09.12 .03\end{array}$ & 27 & 66 & 57 & 47 & 57 & Winter \\
\hline & $\# 2-C$ & 20 & $\begin{array}{l}09.12 .04 \text { } \\
09.12 .17\end{array}$ & 13 & 55 & 37 & 45 & 46 & Winter \\
\hline & $\# 5$ & 30 & $\begin{array}{l}10.07 .26- \\
10.09 .20\end{array}$ & 56 & 103 & 229 & 127 & 153 & Summer \\
\hline & Avg. & & & & 103 & 140 & 98 & 113 & \\
\hline
\end{tabular}

\subsection{Odor concentration of malodorous gas emitted from} sewage mixed with microbial deodorant KS5O in the combined sewer

Table 7 summarizes the results of odorant concentration survey in sewage mixed with microbial deodorant KS50. As shown in Table 7, the average odor concentration of sewage mixed with microbial deodorant in the experimental period was $113 \mathrm{OU}_{\mathrm{k}}$, which was $102 \mathrm{OU}_{\mathrm{k}}$ in winter and $298 \mathrm{OU}_{\mathrm{k}}$ in autumn and $153 \mathrm{OU}_{\mathrm{k}}$ in summer. On the other hand, the odor reduction effect showed a large difference according to the dilution rate to raw KS50 solution. The mean odor concentration when diluted 50 times was found to be $198 \mathrm{OU}_{\mathrm{k}}$, whereas it was $57 \mathrm{OU}_{\mathrm{k}}$ and $46 \mathrm{OU}_{\mathrm{k}}$ when diluted 20 times and 30 times. It also showed a large difference depending on the season. Even when diluted 30 times, the mean odor concentration was $57 \mathrm{OU}_{\mathrm{k}}$ in winter and $153 \mathrm{OU}_{\mathrm{k}}$ in summer, which is about 2.7 times higher than that in winter. The average odor concentration of Test \#2-A in autumn was $198 \mathrm{OU}_{\mathrm{k}}$, which was higher than that of Test \#5 $153 \mathrm{OU}_{\mathrm{k}}$ conducted in the summer. This is because the dilution rate of the Test \#2-A experiment is 50 times higher than 30 times of Test \#5, which is considered to be due to the fact that the odor reduction effect by the microbial deodorant is much lowered.

\subsection{Evaluation of abatement effect of sewer odor by microbial deodorant KS5O}

Table 8 summarizes the odor reduction effect of microbial deodorant KS50 by season, using the odor concentration in the raw sewage and the odor concentration in sewage mixed with microbial deodorant KS50. In autumn, the odor reduction rate by the microbial deodorant KS50 of 50 times diluted was 52\%, which was not so high. When the dilution rate was 20 times and 30 times to raw KS50 solution in winter, the odor reduction rate was 
individually $82 \%$ and $86 \%$ and showed the very high removal efficiency, comparing than other tests. In the experiment conducted at 30 times of dilution rate in summer with relatively high concentration of sewer odor, the odor reduction rate was about $77 \%$. Judging comprehensively, it is estimated that the sewage odor reduction efficiency of microbial deodorant KS50 is about $75 \%$.

Table 8. Evaluation of odor reduction effect by microbial deodorants KS50

\begin{tabular}{|c|c|c|c|c|c|c|c|c|c|}
\hline \multirow[b]{2}{*}{ Test } & \multirow[b]{2}{*}{ Source } & \multirow{2}{*}{$\begin{array}{l}\text { Dilution } \\
\text { ratio to } \\
\text { raw KS50 } \\
\text { solution }\end{array}$} & \multirow[b]{2}{*}{ Date } & \multirow[b]{2}{*}{$\begin{array}{l}\text { Period } \\
\text { (days) }\end{array}$} & \multicolumn{4}{|c|}{ Odor concentration in average $\left(O U_{k}\right)$} & \multirow[b]{2}{*}{ Season } \\
\hline & & & & & Site-1 & Site-2 & Site-3 & Avg. & \\
\hline$\# 1$ & $\begin{array}{c}\text { Raw } \\
\text { sewage }\end{array}$ & - & $\begin{array}{l}\text { '09.09.01 - } \\
` 09.10 .20\end{array}$ & 50 & 498 & 415 & 323 & 412 & Autumn \\
\hline \multirow[t]{2}{*}{$\# 2-A$} & $\begin{array}{c}\text { Sewage } \\
\text { mixed } \\
\text { with KS50 }\end{array}$ & 50 times & $\begin{array}{l}\text { 09.10.21 } \\
\text { '09.11.05 }\end{array}$ & 57 & 186 & 235 & 174 & 198 & Autumn \\
\hline & & \multicolumn{3}{|c|}{ Removal Efficiency (50 times) } & $63 \%$ & $43 \%$ & $46 \%$ & $52 \%$ & \\
\hline \#3 & $\begin{array}{c}\text { Raw } \\
\text { sewage }\end{array}$ & - & $\begin{array}{l}\text { 09.12.18 - } \\
10.02 .28\end{array}$ & 45 & 261 & 391 & 311 & 321 & Winter \\
\hline \#2-B & $\begin{array}{c}\text { Sewage } \\
\text { mixed } \\
\text { with KS50 }\end{array}$ & 30 times & $\begin{array}{l}` 09.11 .06 \text { } \\
` 09.12 .03\end{array}$ & 27 & 66 & 57 & 47 & 57 & Winter \\
\hline \multirow[t]{3}{*}{$\# 2-C$} & $\begin{array}{c}\text { Sewage } \\
\text { mixed } \\
\text { with KS50 }\end{array}$ & 20 times & $\begin{array}{l}\text { '09.12.04 } \\
\text { `09.12.17 }\end{array}$ & 13 & 55 & 37 & 45 & 46 & Winter \\
\hline & & \multicolumn{3}{|c|}{ Removal Efficiency (30 times) } & $75 \%$ & $85 \%$ & $85 \%$ & $82 \%$ & \\
\hline & & \multicolumn{3}{|c|}{ Removal Efficiency (20 times) } & $79 \%$ & $91 \%$ & $86 \%$ & $86 \%$ & \\
\hline$\# 4$ & $\begin{array}{c}\text { Raw } \\
\text { sewage }\end{array}$ & - & $\begin{array}{l}\text { '10.06.01 - } \\
` 10.07 .26 \\
\end{array}$ & 56 & 361 & 894 & 722 & 659 & Summer \\
\hline \multirow[t]{3}{*}{ \#5 } & $\begin{array}{c}\text { Sewage } \\
\text { mixed } \\
\text { with KS50 }\end{array}$ & 30 times & $\begin{array}{l}10.07 .26 \text { - } \\
' 10.09 .20\end{array}$ & 56 & 103 & 229 & 127 & 153 & Summer \\
\hline & \multicolumn{4}{|c|}{ Removal Efficiency (30 times) } & $71 \%$ & $74 \%$ & $82 \%$ & $77 \%$ & \\
\hline & Removal E & ciency in av & & & & & & $74 \%$ & \\
\hline
\end{tabular}

\section{Conclusions}

It would have been very difficult to investigate more than 1000 odor samples, if the existing technology such like dynamic olfactometer of Europe or triangular bag method of Japan were used for the collected grab samples in this study.

This study shows the new technology to monitor the odor occurrence situation at the remote site in real time and the technology to reduce sewage odor by using microbial deodorant. Long-term monitoring and full-scale test was carried out to investigate the odor concentration in the combined sewer using the real - time odor monitoring device which consist of 3 odor sensors with the wireless communication technique, and to investigate the effect of the microbial deodorant on the reduction of sewer odor. Odor monitoring in field was carried out at the interval of 10 minutes for 304 days over the autumn, winter and summer. The measured results were transmitted to odor research center in Woo Song University about $100 \mathrm{~km}$ away from the site. The measured sensor value was converted to olfactory odor concentration by the co-relation equation of the sensor value and the olfactory odor concentration.

As the study results, the new technology was very useful to monitor automatically odor occurrence situation in real- time. Since the odor monitoring was performed at the interval of 10 minutes during the experimental period, it was possible to accumulate more than 40,000 odor data and could be monitored the complaints possibility due to sewer odor in real time.

On the basis of the analyzed results of the observed sewer odor data, the average odor concentration of raw sewage in combined sewer was $464 \mathrm{OU}_{\mathrm{k}}$, which was $321 \mathrm{OU}_{\mathrm{k}}$ in winter and $412 \mathrm{OU}_{\mathrm{k}}$ in autumn and $659 \mathrm{OU}_{\mathrm{k}}$ in summer. The commercial microbial deodorant used in this study was the mixture culture of 48 microbial strains, and the microbial deodorant of $1 \mathrm{~m}^{3} \mathrm{~d}^{-1}$ to $2 \mathrm{~m}^{3} \mathrm{~d}^{-1}$ was mixed with raw sewage at the $1.5 \mathrm{~km}$ upstream of the site where odor complaints occurred. As the experimental results, the average odor concentration of sewage mixed with microbial deodorant was $113 \mathrm{OU}_{\mathrm{k}}$, which was $102 \mathrm{OU}_{\mathrm{k}}$ in winter and $298 \mathrm{OU}_{\mathrm{k}}$ in autumn and $153 \mathrm{OU}_{\mathrm{k}}$ in summer. It was estimated that the odor reduction effect of sewer odor by microbial deodorant is about $74 \%$.

On the other hand, in the experiment of sewer odor abatement technique using microbial deodorant, since microbial deodorant injection into the sewer was carried out by manpower, there were many limitations to operate effectively in the field. If the automatic injection technique of adding microbial deodorant is added to this technology, when high concentration odor in the sewer is detecting by 
the odor sensor in real time, this technology which consists of odor sensor monitoring device and microbial deodorization technique can be used more effectively in the future.

\section{Acknowledgments}

This study was conducted under the support of Woosong University and Seoul Metropolitan City. I would like to appreciate the two organizations for their research fund and field experiments support.

\section{References}

Chen G.H. and Leung D.H. (2000), Utilization of oxygen in a sanitary gravity sewer, Journal of Elsevier Science, 34, 38133821.

Cipriani M., Schiavi R. and Santos F. (2017), A successful experience in Sorocaba city - Brazil, Proceeding of $7^{\text {th }}$ IWA Odours and Air Emissions Conference Abstracts List, 4B(4).

Dan F., Eran F. and Ori L. (2008), Control of sulfide in sewer system by dosage of iron salts: comparison between theoretical and experimental results, and practical implications, Science of the Total Environment, 392, 145-156.

Forbes R.H., Hux D., Cummings L. and Goodwin S.M. (2002), Three-step process to success in controlling wastewater collection system odors in Gastonia, North Carolina, 2002 Water Environment Federation. Retrieved from https://www.researchgate.net/publication/272275392.

Three-step process to success in controlling wastewater collection system odors in gastonia North Carolina.

Ishida H., Yamanaka T., Kushida N., Nakamoto T. and Moriizumi T. (2000), Study of real-time visualization of gas odor flow image using gas sensor array, Journal of Sensors and Actuators, B65, 14-16.

Japan Association of Odor Environment. (1992), Mannual of practice: odor prevention technology of septic tank and building pit.

Jin P.S. and Youl K.S. (2014), Odor Characteristics of Malodorous Sulfur-containing Gas Emitted from a Sewer and Its Outlet. Journal of Korean Society of Environmental Health, 40, 477-483.

Jin P.S. and Youl K.W. (2017), Characteristics and Concentration of Malodorous Volatile Organic Compounds Emitted from a Sewer and Its Outlet. Journal of Korean Society of Environmental Health, 43, 457-466.

Joo S.W. and Park S.J. (2006), Recent development of e-nose as odor sensors, Korean Journal of Odor Research and Engineering, 5, 171-179.

Kim J., Sekyama K., Lee D.W. and Kim H.W. (2006), Odors from Wastewater treatment plants, Korean Journal of Odor Research and Engineering, 5, 180-192.

Mathioudakis V.L., Vaiopoulou E. and Aivasidis A. (2006), Addition of nitrate for odor control in sewer networks: Laboratory and field experiments, Global NEST Journal, 8, $37-42$.

National Institute of Environmental Research. (2005), Standard method of odor estimation and malodorous compounds in Korea.

Pan L. and Simon X.Y. (2009), An Electronic Nose Network System for Online Monitoring of Livestock Farm Odors, Journal of ASME Transactions on Mechatronics, 14, 371-376.
Peter C. and David E. (1999), Hydrogen sulfide odor control in wastewater collection systems, NEWEA Journal, 33, 57-63.

Schattovits G., Nowak R. and Rupp R. (2000), Solving the problem of odour emission from Vienna's sewer system: Three case studies, Proceeding of $1^{\text {st }}$ IWA International conference on odour and VOCs: Measurement, Regulation and Control Techniques, 295-302.

Seoul Development Institute. (2009), A study on the reduction solution for sewer foul odor discharged from a septic tank.

Seoul Metropolitan City. (2018), Innovative technology seminar to abate odor emitted from sanitary sewer in downtown of city.

Seoul Seocho District. (2010), Full-scale project to reduce odor problem of the sanitary trunk sewer in Seocho district of Seoul city.

Shakoorjavan S., Akbari S., Kish M.H. and Akbare M. (2016), Correlation of sensory analysis with a virtual sensor array data for odour diagnosis of fragrant fabrics, Journal of Measurement, 90, 396-403.

Son M., Cho D., Lim J.H., Park J., Hong S., Ko H.J. and Park T.H. (2015), Real-time monitoring of geosmin and 2methylisoborneol, representative odor compounds in water pollution using bioelectronic nose with human-like performance, Biosensors and Bioelectronics Journal, 74, 199-206.

Witherspoon J.R., Densing W., Siczka J., Zammit C. and Underwood B. (2017), Integrating odour nuisance impacts and combined control strategies from city of San Mateo's wastewater conveyance system through wastewater treatment plant processes, Proceeding of $7^{\text {th }}$ IWA Odours and Air Emissions Conference Abstracts List, 4B(3).

Zhang L., Schryver P.D., Gusseme B.D., Muynck W.D., Boon N. and Verstraete W. (2008), Chemical and biological technologies for hydrogen sulfide emission control in sewer systems: A review, Journal of Water Research, 42, 1-12.

Zhang L., Tian F.-C., Peng X.-W. and Yin X. (2014), A rapid discreteness correction scheme for reproducibility enhancement among a batch of MOS gas sensors, Journal of Sensors and Actuators, A205, 170-176. 